\title{
Water distribution and clustering on lyophilized IgG1 surface: insight from molecular dynamics simulations
}

\author{
Feng, Shaoxin; Peters, Günther H.J.; Ohtake, Satoshi; Schoneich, Christian; Shalaev, Evgenyi
}

Published in:

Molecular Pharmaceutics

Link to article, DOI:

10.1021/acs.molpharmaceut.9b01150

Publication date:

2020

Document Version

Peer reviewed version

Link back to DTU Orbit

Citation (APA):

Feng, S., Peters, G. H. J., Ohtake, S., Schoneich, C., \& Shalaev, E. (2020). Water distribution and clustering on lyophilized IgG1 surface: insight from molecular dynamics simulations. Molecular Pharmaceutics, 17(3), 900908. https://doi.org/10.1021/acs.molpharmaceut.9b01150

\section{General rights}

Copyright and moral rights for the publications made accessible in the public portal are retained by the authors and/or other copyright owners and it is a condition of accessing publications that users recognise and abide by the legal requirements associated with these rights.

- Users may download and print one copy of any publication from the public portal for the purpose of private study or research.

- You may not further distribute the material or use it for any profit-making activity or commercial gain

- You may freely distribute the URL identifying the publication in the public portal 


\section{Water distribution and clustering on lyophilized IgG1}

surface: insight from molecular dynamics simulations

Shaoxin Feng, Günther H. J. Peters, Satoshi Ohtake, Christian Schoneich, and Evgenyi Shalaev

Mol. Pharmaceutics, Just Accepted Manuscript • DOI: 10.1021/acs.molpharmaceut.9b01150 • Publication Date (Web): 28 Jan 2020

Downloaded from pubs.acs.org on February 3, 2020

\section{Just Accepted}

"Just Accepted" manuscripts have been peer-reviewed and accepted for publication. They are posted online prior to technical editing, formatting for publication and author proofing. The American Chemical Society provides "Just Accepted" as a service to the research community to expedite the dissemination of scientific material as soon as possible after acceptance. "Just Accepted" manuscripts appear in full in PDF format accompanied by an HTML abstract. "Just Accepted" manuscripts have been fully peer reviewed, but should not be considered the official version of record. They are citable by the Digital Object Identifier (DOI®). "Just Accepted" is an optional service offered to authors. Therefore, the "Just Accepted" Web site may not include all articles that will be published in the journal. After a manuscript is technically edited and formatted, it will be removed from the "Just Accepted" Web site and published as an ASAP article. Note that technical editing may introduce minor changes to the manuscript text and/or graphics which could affect content, and all legal disclaimers and ethical guidelines that apply to the journal pertain. ACS cannot be held responsible for errors or consequences arising from the use of information contained in these "Just Accepted" manuscripts. 


\section{Water distribution and clustering on lyophilized IgG1 surface: insight from molecular dynamics simulations}

Shaoxin Feng ${ }^{1 *}$, Günther H.J. Peters ${ }^{2}$, Satoshi Ohtake ${ }^{3}$, Christian Schöneich ${ }^{4}$, Evgenyi Shalaev ${ }^{1 *}$

1. Department of Pharmaceutical Development, Allegan PLC., Irvine, CA

2. Department of Chemistry, Technical University of Denmark, 2800 Kgs. Lyngby, Denmark

3. BioTherapeutics Pharmaceutical Sciences, Pfizer, Chesterfield, MO

4. Department of Pharmaceutical Chemistry, University of Kansas, KS

*Corresponding Authors: feng_shaoxin@allergan.com; Evgenyi.Shalaev@,Allergan.com

Department of Pharmaceutical Development, Allergan PLC., 2525 Dupont Drive, Irvine, CA, 92612, USA

Phone: +1 (714) 246-6271 (SF), +1 (714) 246-3372 (ES)

Fax: +1 (714) 796-9579 (SF), +1 (714) 569-9058 (ES) 


\title{
TOC/Abstract Graphic:
}
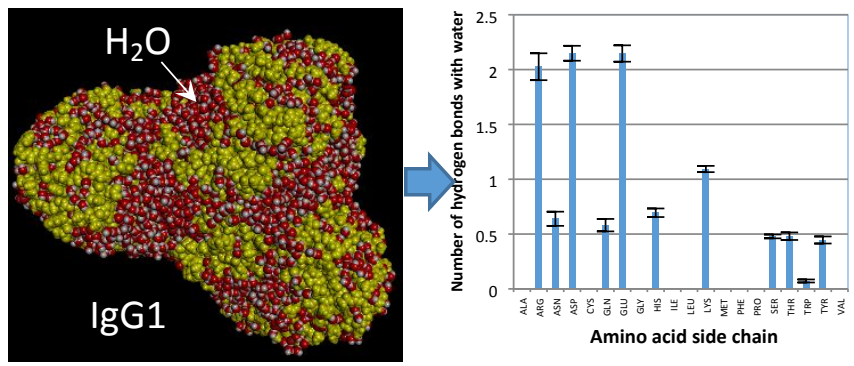

\begin{abstract}
Water has a critical role in the stability of the higher-order structure of proteins. In addition, it is considered to be a major destabilization factor for the physical and chemical stability of freeze-dried proteins and peptides. Physical chemical aspects of protein/water relationships are commonly studied with the use of water vapor sorption isotherms for amorphous lyophilized proteins, which, in turn, are commonly analyzed using the Brunauer-Emmett-Teller (BET) equation to obtain the parameters, $W_{\mathrm{m}}$ and $C_{\mathrm{B}}$. The parameter $W_{\mathrm{m}}$ is generally referred to as the "monolayer-limit of adsorption" and has a narrow range of $6-8 \%$ for most proteins. In this study, the water distribution on an IgG1 surface is investigated by molecular dynamics (MD) simulations at different water contents. The monolayer of water molecules was found to have limited coverage of the protein surface, and the true monolayer coverage of the protein globule actually occurs at a hydration level above $30 \%$. The distribution of water molecules on the IgG1 surface is also highly heterogeneous, and the heterogeneity is not considered in the BET theory. In this study, a mechanistic model has been developed to describe the water vapor sorption isotherm. This model is based on the analysis of the hydrogen bonding network extracted from the MD simulations. The model is consistent with the experimental Type-II isotherm, which is usually observed for proteins. The physical meaning of the BET monolayer was re-defined as onset of water cluster formation. A simple model to calculate the onset water level, $W_{\mathrm{m}}$, is proposed based on the hydration of different amino acids, as determined from the MD simulations.
\end{abstract}

\section{Keywords:}

Water sorption; lyophilized protein; molecular dynamic simulation; water distributions on protein surface; BET monolayer. 


\section{INTRODUCTION}

Therapeutic proteins (biologics) provide important therapies for a variety of diseases, such as diabetes ${ }^{1}$, cancer $^{2}$, infectious diseases ${ }^{3}$, hemophilia ${ }^{4}$, and anemia ${ }^{5}$. Although liquid formulations are usually preferred for injectable biologics, this form is not always feasible given the high molecular sensitivity of proteins to mechanical stresses, temperature, and other environmental factors that can lead to protein denaturation, aggregation, and degradation ${ }^{6}$. One approach to overcome some of the problems is lyophilization, and many therapeutic proteins are produced as freeze-dried powders for reconstitution to improve their stability and shelf life ${ }^{7-9}$. In freeze-dried proteins, water is usually considered as a major destabilization factor under the assumption that an increase in water content results in an acceleration of all degradation reactions ${ }^{10,11}$. As a result, water relationships in dried proteins and other amorphous pharmaceuticals have been extensively studied. In particular, structural aspects of water in partially hydrated proteins have been investigated in some detail, with the majority of studies focusing on the analysis of the water sorption isotherms (i.e., relationships between water activity and water content $)^{12,13}$. In pharmaceutical systems, the most common approach involves application of the BET model, in which the equation developed for adsorption of solvents on solid surfaces has been applied to analyze water sorption isotherms for dried proteins. The result of such analysis is usually the determination of water monolayer (explained in more detail below) ${ }^{12,14}$. In the polymer science literature, the water sorption isotherms for proteins and other polymers have been analyzed using the Zimm-Lundberg solvent cluster integral ${ }^{15}$. In these studies, a water content/activity threshold is determined, above which there is a qualitative change in water structure (i.e., either starting adsorption by forming a second layer of water, or formation of water clusters). The water content threshold can be described as critical water content. But at the critical water content forming "monolayer" (typically 6-8 $\mathrm{wt} \%$ ), the water coverage on the protein surface is scattered and only at a hydration level of $30-40 \%$, a true monolayer coverage of the protein globule actually occurs ${ }^{16}$. It should also be noted that, even if these approaches are completely valid, they do not provide a detailed spatial picture of water distribution. In this respect, computer simulations can supply information on water distribution around a protein molecule with atomistic resolution ${ }^{17}$. Details of water distribution for a protein molecule are essential for the mechanistic understanding of various phenomena ${ }^{18}$, including e.g., chemical reactions such as deamidation ${ }^{19}$ and drug/receptor interactions ${ }^{20}$. There are numerous molecular dynamics (MD) simulation studies on water relationships in proteins ${ }^{21-23}$. Heyden studied the ubiquitin-water system and found that water molecules have a preferred orientation up to 10-15 $\AA$ distance from the protein while the water number density converges to bulk density within $<8 \AA^{21}$. Urbic and Dias examined the 
hydration of non-polar anti-parallel beta-sheets and found that water distribution around the backbone does not depend significantly on amino acid sequence ${ }^{22}$. Ben-Shalom et al. improved the MD methodology and could simulate water exchange/access to buried binding sites of proteins by using Monte-Carlo molecular dynamics (MC/MD) technique, since traditional MD method would require significantly longer time for simulations to converge ${ }^{23}$. In the absolute majority of these studies, however, systems with an excess of water were studied. Investigations of water distribution in partially hydrated protein systems are sparse ${ }^{24-26}$.

In the present study, the dynamics and structure of water molecules on a partially hydrated human antibody (IgG1 b12) surface were investigated using MD simulations. At relatively high water hydration levels, water molecules do not cover completely the protein surface but instead form clusters. From the number of hydrogen bonds between water molecules and amino acids, an alternative approach, where the key parameters were obtained from MD simulations, was developed to calculate the water sorption isotherm on the lyophilized protein. The relationship between the mechanistic theory and phenomenological BET theory is discussed, and the physical meaning of the BET monolayer was re-defined as applied to a protein/water system. A simple model to calculate the critical water level is proposed based on the hydration of different amino acids, as determined from the MD simulations. The Zimm-Lundberg clustering integral was also tested, and the model is found to be not applicable to the protein/water system.

\section{METHODS}

\section{Molecular Dynamics Simulations:}

Molecular dynamics (MD) simulations were carried out using NAMD version $2.8^{27}$. MD simulations were performed on the crystal structure of human IgG1 b12 resolved to $2.7 \AA^{28}$. The structure was obtained from the Protein Data Bank; pdb entry code $1 \mathrm{hzh}^{29}$. The CHARMM36 all hydrogen parameter set $^{30}$ with the TIP3 water model ${ }^{31}$ was applied. Solvation shells with different numbers of water molecules $\left(N_{\text {water }}\right)$ were considered; $N_{\text {water }}=202,407,725,1133,1848,2464$, and 3169. The initial structures with the desired solvation shell were generated by placing water molecules around certain amino acid side chains and/or backbone amide groups with details shown in Table 1. Each system was initially energy-minimized for 2500 steps using the conjugate gradient algorithm within NAMD ${ }^{27}$. Two simulations of systems with $N_{\text {water }}=202,407$ and 2464 were considered to assess the statistical uncertainties in the simulation results. For $N_{\text {water }}=202$ and 407, two different solvation shell procedures were used to study the effect of initial water configurations, whereas for $N_{\text {water }}=2464$, two different 
minimizations (2500 and 5000 steps) were applied. The simulations were started by heating the systems to $T=300 \mathrm{~K}$ within $100 \mathrm{ps}$ using a time step of $1 \mathrm{fs}$. This was followed by the production runs of 120-150 ns. The temperature was maintained at $T=300 \mathrm{~K}$ using the Langevin dynamics method ${ }^{32}$ with a Langevin damping coefficient of $\gamma=5 \mathrm{ps}^{-1}$. Interactions were cut-off at $12 \AA$ in combination with a switching function starting at $10 \AA$. The cut-off of the neighboring (pair) list was set to $14 \AA$ and updated every 2 fs. The non-bonded interactions were updated every 1 fs. Configurations were saved every 500 fs. Analyses of the trajectories were performed using the graphical program Visualization Molecular Dynamics, VMD, ${ }^{33}$ along with in-house tcl-scripts.

Table 1, Initial locations of water molecules on the protein with varying number of adsorbed water molecules. The number behind each amino acid type indicates the number of placed water molecules on each of the specified amino acid side chain.

\begin{tabular}{|c|c|}
\hline $\begin{array}{l}\text { Number of water } \\
\text { molecules }\end{array}$ & Initial locations on the protein \\
\hline 725 & Arg-1, Asn-1, Asp-1, Gln-1, Glu-1, His-1, Lys-1, Ser-1, Thr-1, Tyr-1 \\
\hline 1133 & Arg-5, Asn-2, Gln-2, His-1, Lys-3, Ser-1, Thr-1, Trp-1, Tyr-1 \\
\hline 2464 & $\begin{array}{l}\text { Arg-5, Asn-2, Gln-2, His-1, Lys-3, Ser-1, Thr-1, Trp-1, Tyr-1, Backbone } \\
\text { carbonyl-1 }\end{array}$ \\
\hline 3169 & $\begin{array}{l}\text { Arg-5, Asn-3, Asp-2, Gln-3, Glu-2, His-2, Lys-3, Ser-2, Thr-2, Trp-1, Tyr-2, } \\
\text { Backbone carbonyl-1, }\end{array}$ \\
\hline $407_{1}$ & Asp-1, Glu-1, Ser-1, Thr-1, Tyr-1 (remove 33 randomly) \\
\hline $407_{2}$ & $\begin{array}{l}\text { Subset of } 725 \mathrm{H}_{2} \mathrm{O} \text { molecules (after energy minimization). The subset has } \\
\text { more protein-water hydrogen bonds }(\geq 2)\end{array}$ \\
\hline $202_{1}$ & \multirow{2}{*}{$\begin{array}{l}\text { Split } 407 \mathrm{H}_{2} \mathrm{O} \text { molecules (1st set, after energy minimization) into } 2 \text { subsets, } \\
\text { all } \mathrm{H}_{2} \mathrm{O} \text { molecules around Glu and Asp residues are in } 202_{1} \text { subset. }\end{array}$} \\
\hline $202_{2}$ & \\
\hline
\end{tabular}

To analyze the structure at any given simulation time frame, the hydrogen bonds in the system were examined. For hydrogen bonds A-H...B, where A and B could be oxygen or nitrogen, the criteria for a hydrogen bond were: $\mathrm{d}_{\mathrm{A}, \mathrm{B}}<3.9 \AA, \mathrm{d}_{\mathrm{H}, \mathrm{B}}<3.0 \AA$, and $\angle \mathrm{A}, \mathrm{H}, \mathrm{B}=120^{\circ}$. The hydrogen bonds within IgG1, between water molecules and IgG1, as well as between different water molecules were counted. For the protein, hydrogen bonds formed by amino acid side groups and backbone amides were separately examined.

\section{THEORY}




\section{Water Sorption on Protein}

The water sorption on protein surfaces is highly heterogenic ${ }^{21}$, due to a distribution of sorption sites with different strengths of hydrogen bonds. The strength of binding for each water sorption site depends on the number of hydrogen bonds (HB) formed between water molecules and residues as well as the energies of individual hydrogen bonds. In general, the larger the number of hydrogen bonds is the stronger is the binding. In this line, although all the interactions, e.g. hydrogen bonding, electrostatic, and van der Waals potentials, are taken into account in the MD simulations, only hydrogen bonding networks are considered for further analysis because hydrogen bonds are the major short-range interactions. Since the hydrogen bonds are highly dynamic and can form and break in a short period of time (ps to ns range in the studied system), the energy of individual hydrogen bonds would also change rapidly. If the average energy of individual hydrogen bonds is assumed to be constant, the number of hydrogen bonds can be used to characterize the strength of water binding on the protein surface. Based on the number of hydrogen bonds formed with the protein, the adsorbed water molecules were classified into 6 groups: water can form 0 , 1, 2, 3, 4, and 5 hydrogen bonds ${ }^{34}$. The corresponding groups are Group 0, 1, 2, 3, 4, and 5. Besides Group 0, all the other 5 groups have finite numbers of water molecules because each protein molecule can form a finite number of hydrogen bonds with water molecules. The saturated levels or the maximum numbers of water molecules in the 5 groups were labeled as $N_{1}, N_{2}, N_{3}, N_{4}$, and $N_{5}$. The energy levels of the five water groups are also different with labels of $E_{1}, E_{2}, E_{3}, E_{4}$, and $E_{5}$. The water molecules in Group 1 to 5 could all be considered as the "first layer" of adsorbed water because there are direct hydrogen bonds between the water molecules and the protein. This "first layer" water is also significantly more than a conventional BET monolayer (usually 6-8\%) because the water molecules in this "first layer" could form hydrogen bonds both with protein and other water molecules in the "first layer" leading to the formation of water clusters. The Group 0 will include water at the truly second layer and above. At low water activity $(<0.4)$, only the second water layer was considered. The saturation level for the second layer water is defined as $N_{0}$ and the corresponding energy level is $E_{0}$.

When water activity is $a_{w}$, the following equation holds:

$$
a_{w}=e^{\frac{\mu}{R T}}
$$

where $\mu$ is the chemical potential of water vapor, $R$ is the gas constant, and $T$ is the absolute temperature. If the water sorption on a binding site of protein is independent from other binding sites in the first layer, the water occupation fraction in each group follows Thomas-Fermi statistics: 


$$
\frac{n_{i}}{N_{i}}=\frac{1}{e^{\frac{E_{i}-\mu}{R T}}+1}
$$

where $n_{\mathrm{i}}$ is the number of adsorbed water molecules in Group i. The above equation is also equivalent to the Langmuir adsorption model. For the second layer water, Group 0, the fraction of water occupation depends on the first layer water:

$$
n_{0}=\frac{1}{e^{\frac{E_{0}-\mu}{R T}}+1} \sum_{i=1}^{5} n_{i}
$$

The total number of water molecules sorbed at a specific water activity can be calculated as:

$$
n_{\text {total }}=\sum_{i=1}^{5} n_{i}=\left(1+\frac{1}{e^{\frac{E_{0}-\mu}{R T}}+1}\right) \sum_{i=1}^{5} \frac{N_{i}}{e^{\frac{E_{i}-\mu}{R T}}+1}=\left(1+\frac{1}{e^{\frac{E_{0}}{R T}} / a_{w}+1}\right) \sum_{i=1}^{5} \frac{N_{i}}{e^{\frac{E_{i}}{R T}} / a_{w}+1}
$$

The weight of water adsorbed per dry weight of lyophilized protein, $W$, can be calculated as:

$$
W=\frac{n_{\text {total }} M W_{\mathrm{H}_{2} \mathrm{O}}}{M W_{\text {protein }}}=\frac{M W_{\mathrm{H}_{2} \mathrm{O}}}{M W_{\text {protein }}}\left(1+\frac{1}{e^{\frac{E_{0}}{R T}} / a_{w}+1}\right) \sum_{i=1}^{5} \frac{N_{i}}{e^{\frac{E_{i}}{R T}} / a_{w}+1}
$$

Once the parameters $N_{i}$ and $E_{i}$ are determined, the above equation can be used to calculate the water sorption isotherm of lyophilized protein. This relationship is different from the BET equation ${ }^{35}$ :

$$
W=\frac{W_{m} C_{B} a_{w}}{\left(1-a_{w}\right)\left(1-a_{w}+C_{B} a_{w}\right)}
$$

where $W_{m}$ is the weight of "monolayer" water, and $C_{B}$ is a constant reflecting the energy of adsorption.

\section{Determining $N_{i}$ and $E_{i}$}

The key parameters in the above water sorption model can be determined from molecular dynamics simulations. With increasing number of water molecules bound to the protein molecule, the number of water molecules in the different groups $\left(n_{i}\right)$ classified by the number of hydrogen bonds will also increase and can reach saturation $\left(N_{i}\right)$ at certain water sorption level. For example, water molecules with 5 and 4 HBs with protein $\left(n_{5}\right.$ and $\left.n_{4}\right)$ could reach saturation at relatively lower water sorption level $\left(n_{\text {total }}\right)$; water molecules with fewer number of HBs with the protein (such as $n_{2}$ ) reach saturation at a relatively higher water sorption level. But the water molecules with $n_{1}$ will not reach saturation even at the highest studied $n_{\text {total }}$. To estimate the saturation level for Group 1 water, the maximum hydrogen bond number between a protein and surrounding water molecules could be calculated using total HB donors/acceptors 
( $N_{\text {Protein,HBdonor }}$ and $\left.N_{\text {Protein,HBacceptor }}\right)$ and intra-molecular HB $\left(N_{\text {Intramolecular HB }}\right)$ in a protein molecule:

$$
N_{1}=N_{\text {Protein,HBdonor }}+2 \cdot N_{\text {Protein,HBacceptor }}-2 \cdot N_{\text {Intramolecular HB }}-\sum_{i=2}^{5} i \cdot N_{i}
$$

Here, the saturation HB number for each HB acceptor is estimated as 2 . The saturation number of $2^{\text {nd }}$ layer water molecules was estimated as the summation of first layer water molecules:

$$
N_{0}=\sum_{i=1}^{5} N_{i}
$$

Once all the saturated water sorption numbers $\left(N_{\mathrm{i}}\right)$ are known, the real water distributions $\left(n_{\mathrm{i}}\right)$ at different water sorption levels ( $\left.n_{\text {total }}\right)$ were determined from the MD simulations. Then the energy difference, $E_{i}-\mu$ , can be determined by using Eq. (2). Although all the energy differences could be determined, one energy reference is missing in order to calculate the water sorption isotherm. Here, one experimental data point is used as an input to connect MD simulations and experiments. We chose the water activity at 725 added water molecules (corresponding to $8.9 \mathrm{wt} \%$ water sorption) as $\sim 0.35$ (as a "reference" state). This value is from an experimental vapor sorption isotherm ${ }^{36,13}$.

\section{Critical water content}

There are several attempts in the literature to predict the BET monolayer level, $W_{\mathrm{m}}$, based on the primary structure of the protein. Pauling ${ }^{37}$ proposed one water molecule adsorbed on each polar amino acid side chain at this critical water content. The model can be expressed as:

$$
N_{\text {critical }}=N_{\text {Asp }}+N_{G l u}+N_{\text {Ser }}+N_{T h r}+N_{T y r}+N_{T r p}+N_{H i s}+N_{L y s}+N_{A r g}
$$

Green $^{38}$ found that the predicted critical water content by Pauling's model often overestimate the critical water contents when compared to experiments. The model was modified to remove contributions from amines in the side chains. The argument was that the amines tend to form intra-molecular hydrogen bonding and will not be available for binding to water. The updated model was expressed as:

$$
N_{\text {critical }}=N_{\text {Asp }}+N_{\text {Glu }}+N_{\text {Ser }}+N_{\text {Thr }}+N_{\text {Tyr }}
$$

\section{RESULTS}

\section{Predicted vapor sorption isotherm based on MD simulation}

Due to the dynamic formation/breaking of hydrogen bonds, the numbers of HBs were counted on multiple structural frames (5-10 frames with $1 \mathrm{~ns}$ increments) captured after the MD simulation was run for $50 \mathrm{~ns}$. The numbers of hydrogen bonds between water and the protein were averaged to get statistically meaningful distributions. Figure 1 shows the numbers of water molecules in different sorption groups (Groups 0 to 5; classification based on number of hydrogen bonds between water 
molecules and protein) for 202 and 407 water molecules on one IgG1 molecule. The higher group number indicates higher number of water-protein hydrogen bonds. When two distinct initial configurations of adsorbed water were used to start the MD simulations (details in Table 1), the final distributions curves were well consistent with each other. The convergence of the distribution results suggests that the MD simulations reached equilibrium, and there was no bias on employing different initial water sorption configurations.

Figure 2 summarizes the water molecule distributions when different amounts of water molecules were added onto the protein molecule. The distribution curves shift to the left with increasing water content. At low water content (202 water), the number of $\mathrm{HB}$ formed by each water molecule with the protein peaks at $3 \mathrm{HBs}$ (39\% of water) and there is a large fraction (35\%) of water forming $2 \mathrm{HBs}$ with the protein. When the water content increased to 407 water molecules, the water molecules forming 2 or 3 HB with the protein are still dominant but the rank order switched: $38 \%$ of water molecules formed 2 HBs while $34 \%$ of water molecules formed $3 \mathrm{HBs}$ with the protein. With further increasing water sorption, the peak of the distribution curve shifts to lower HB numbers formed by each water molecule. At the highest studied water sorption (3169 water molecules), there are $36 \%$ of water molecules forming only $1 \mathrm{HB}$ with the protein and $33 \%$ of water molecules forming no $\mathrm{HB}$ with the protein (located at the $2^{\text {nd }}$ or higher water layers). This trend reflects that water molecules will first bind with lower-energy sites on the protein molecule, with more HBs formed with protein. Once the tightly bound sites are occupied, additional water molecules will fill higher-energy sites.

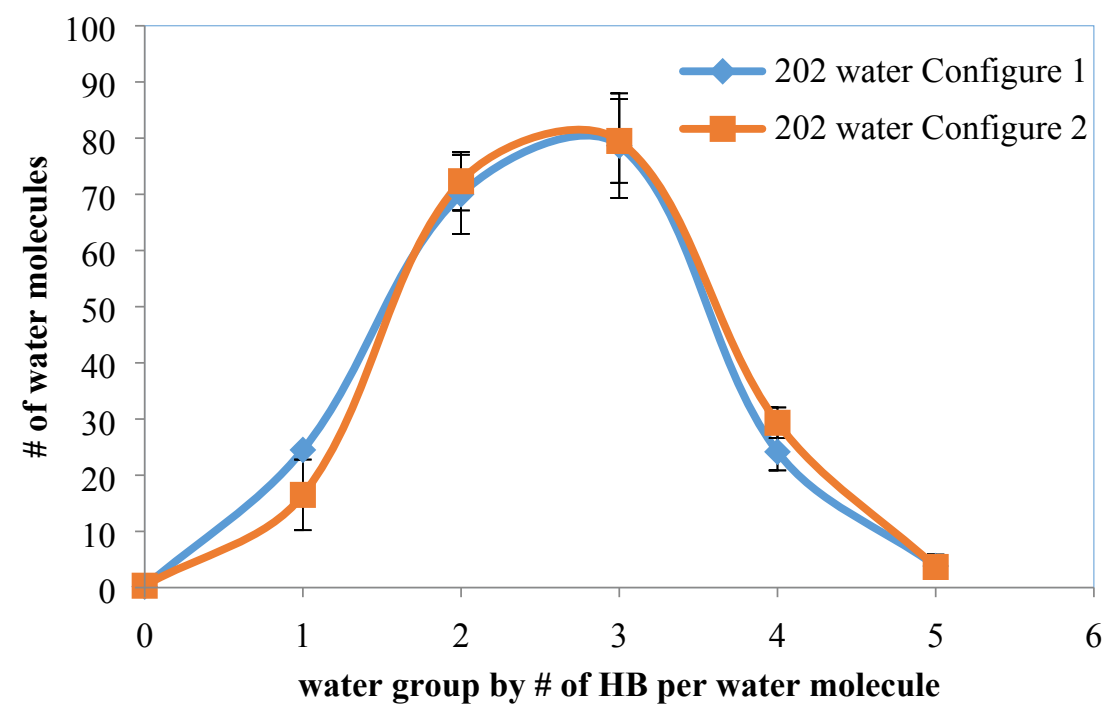

(a) 


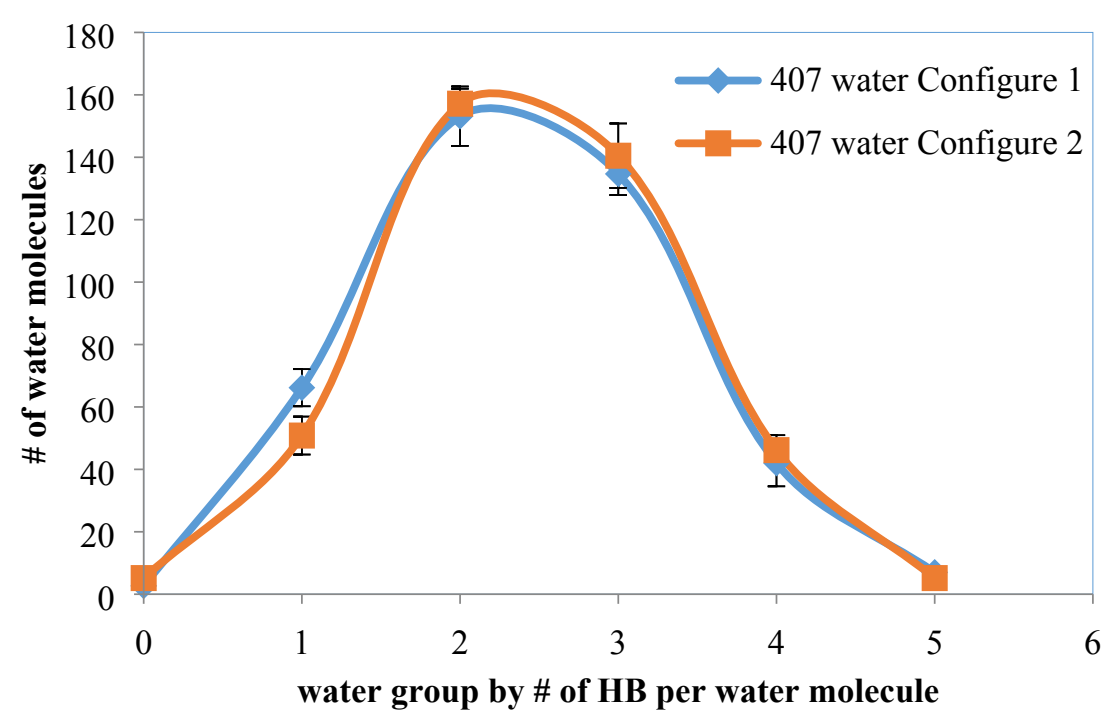

(b)

Figure 1. The distribution of adsorbed water molecules on IgG1 in terms of numbers of hydrogen bonds formed by each water molecule with protein. (a) 202 added water molecules with two different initial structural configurations, 1 and 2; (b) 404 added water molecules with two different initial structural configurations, 1 and 2 .

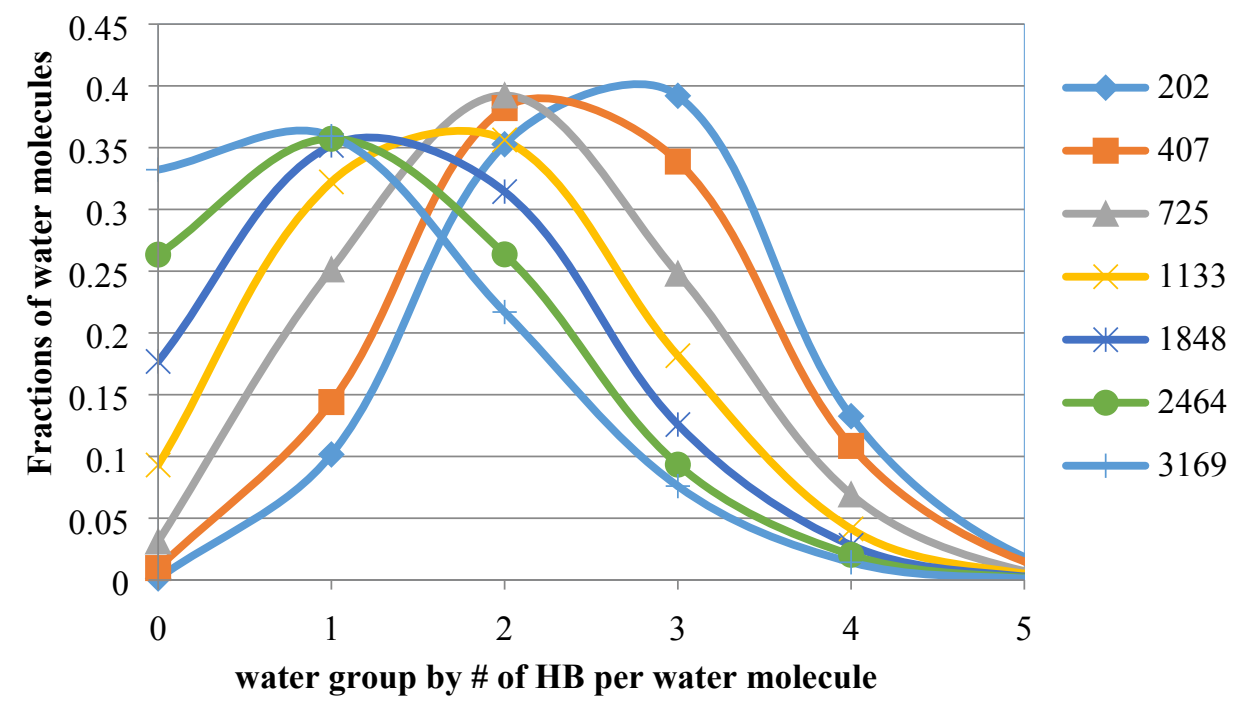

Figure 2. The distribution of adsorbed water molecules on IgG1 in terms of numbers of hydrogen bonds formed by each water molecule with the protein. Different curves correspond to different numbers of adsorbed water molecules.

Figure 3 is based on a conversion of the data from Figure 2 into water molecule numbers in each group $\left(n_{\mathrm{i}}\right)$ as a function of total numbers of adsorbed water molecule $\left(n_{\text {total }}\right)$. The results were used to determine the saturation level of water molecules in each group $\left(N_{\mathrm{i}}\right)$ by fitting the curves to an empirical Weibull model ${ }^{39}$ : 


$$
n_{i}=N_{i}\left[1-e^{-\left(\frac{n_{\text {total }}}{a_{i}}\right)^{\beta}}\right]
$$

where $a_{i}$ is a constant representing how quickly the saturation was reached for water molecules in Group $\mathrm{i}$; the parameter $\beta$ determines the shape of the curve ( 1 for regular first-order curve, $>1$ for sigmoidal shape). For tightly bound water, a first-order equation could fit the data very well using $\beta=1$. The parameters $n_{5}, n_{4}$ and $n_{3}$ reached saturations $-5\left(N_{5}\right), 49\left(N_{4}\right)$, and $235\left(N_{3}\right)$ with $a_{5}=92, a_{4}=220$, and $a_{3}=491$. For loosely bound water in Group 2 , the $n_{\mathrm{i}} v s n_{\text {total }}$ curve shows a sigmoidal trend. A $\beta$ value of 1.24 was used to determine $N_{2}=722$ and $a_{2}=1291$. For Group 1 water, $n_{1}$ was still not close to saturation even at the highest studied $n_{\text {total }}$ (3169). Eq. (7) was used to estimate the saturation level $N_{1}$. At $n_{\text {total }}$ of 3169 , there are 2381 HB donors from the protein $\left(N_{\text {Protein,HBdonor }}\right), 2040 \mathrm{HB}$ acceptors from the protein $\left(N_{\text {Protein,HBacceptor }}\right)$, and 987 intra-molecular HBs formed within the protein molecule. Substituting those values in Eq. (7) gave $N_{1}=2117$. Now all the $N_{\mathrm{i}}$ parameters were determined with the values shown in Table 2. In order to determine the energy levels of different water groups, the water occupation fractions in different water groups $\left(n_{\mathrm{i}} / N_{\mathrm{i}}\right)$ were obtained from MD simulations. Then Eq. (2) was employed to determine the parameters $E_{\mathrm{i}}$ listed in Table 2.

Figure 3 also shows a threshold of approximately 600 water molecules (corresponding to water content of approx. $7 \mathrm{wt} \%$ ), below which all water molecules have at least $1 \mathrm{HB}$ with $\operatorname{IgG} 1$. Above this value, there are water molecules with HB to other water molecules only, i.e., 3-dimensional water clusters. These water clusters can be expected to have properties similar to that of water confined in small pores. For example, freezing behavior of confined water is directly related to the size of the pores, with freezing completely prevented when the radii of pores are smaller than approx. $0.8 \mathrm{~nm}^{40}$. Figure 4 shows the water occupation fractions in different water groups $\left(n_{\mathrm{i}} / N_{\mathrm{i}}\right)$ from MD simulations compared to model fitting by Eq. (2) and $E_{\mathrm{i}}$ values in Table 2. The chemical potentials of water vapor are -1.96 (202 water), -1.13 (407 water), -0.63 (725 water), and -0.21 (1133 water) kcal/mol. The lower $E_{\mathrm{i}}$ values mean stronger water binding to the protein. For water groups 0 and 1 , the $E_{\mathrm{i}}$ becomes positive indicating the water sorption to these sites is energetically unfavorable even at the highest chemical potential of water $\left(a_{\mathrm{w}}=1\right)$. Potential explanation is those loosely bound water molecules have limited gain on binding enthalpy (with one or zero direct HB with protein residues) but have unfavorable entropy (due to structure confinement) compared to water molecule in bulk phase. 


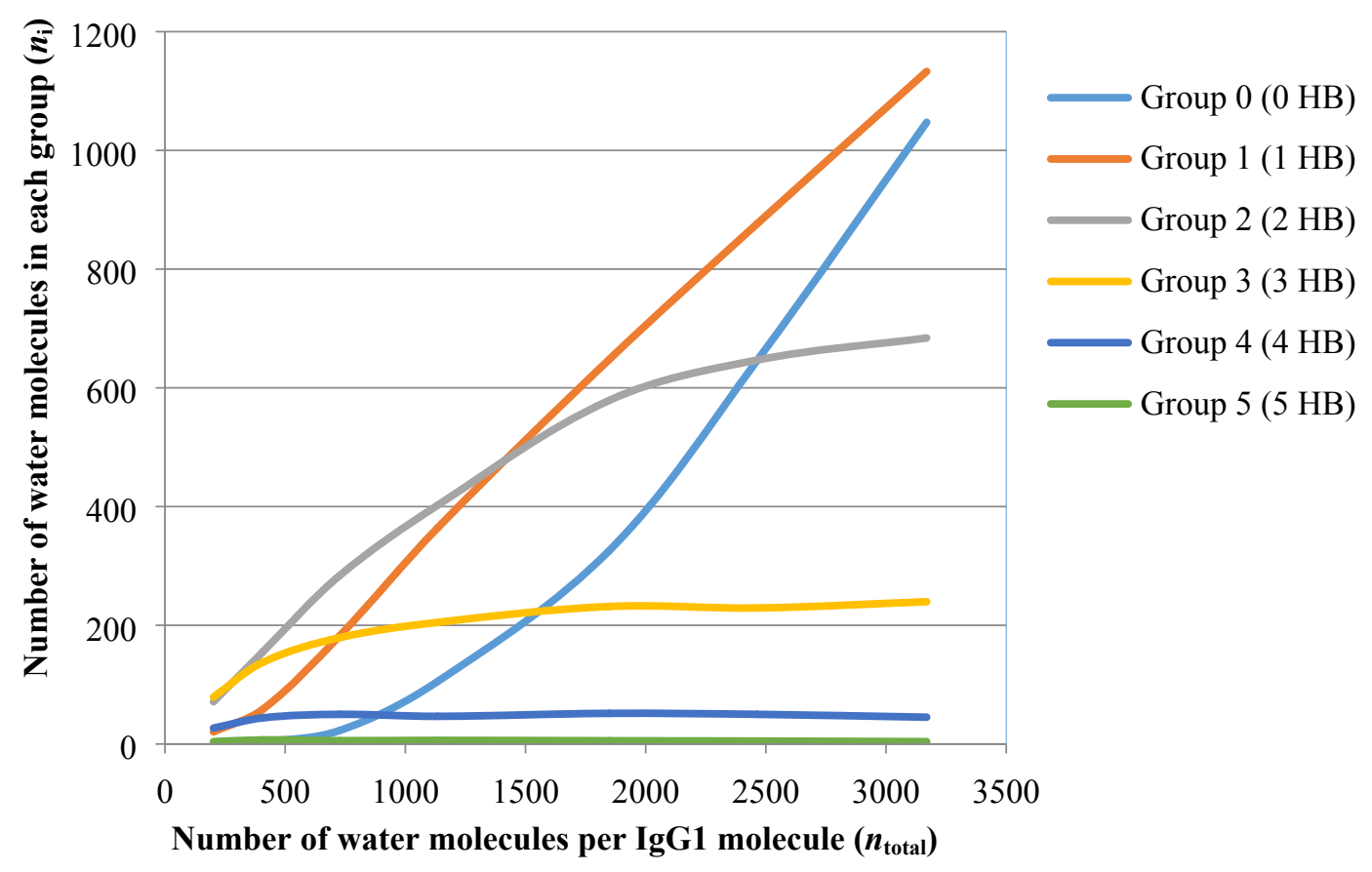

Figure 3. The number of water molecules forming same amount of $\mathrm{HB}$ with protein $(0,1, \ldots 5)$ as a function of total numbers of added water molecules on IgG1 protein.

Table 2. The key parameter $N_{i}$ and $E_{i}$ determined from MD simulations. $i$ is the number of hydrogen bonds formed with IgG1. $N_{i}$ and $E_{i}$ (in Eq. 2) are the saturation water numbers and the energy levels for group $\mathrm{i}$, respectively.

\begin{tabular}{|c|c|c|}
\hline$i$ & $N_{i}$ & $E_{i}(\mathrm{kcal} / \mathrm{mol})$ \\
\hline 0 & 3128 & 1.10 \\
\hline 1 & 2117 & 0.93 \\
\hline 2 & 722 & -0.38 \\
\hline 3 & 235 & -1.40 \\
\hline 4 & 49 & -2.16 \\
\hline 5 & 5 & -2.86 \\
\hline
\end{tabular}




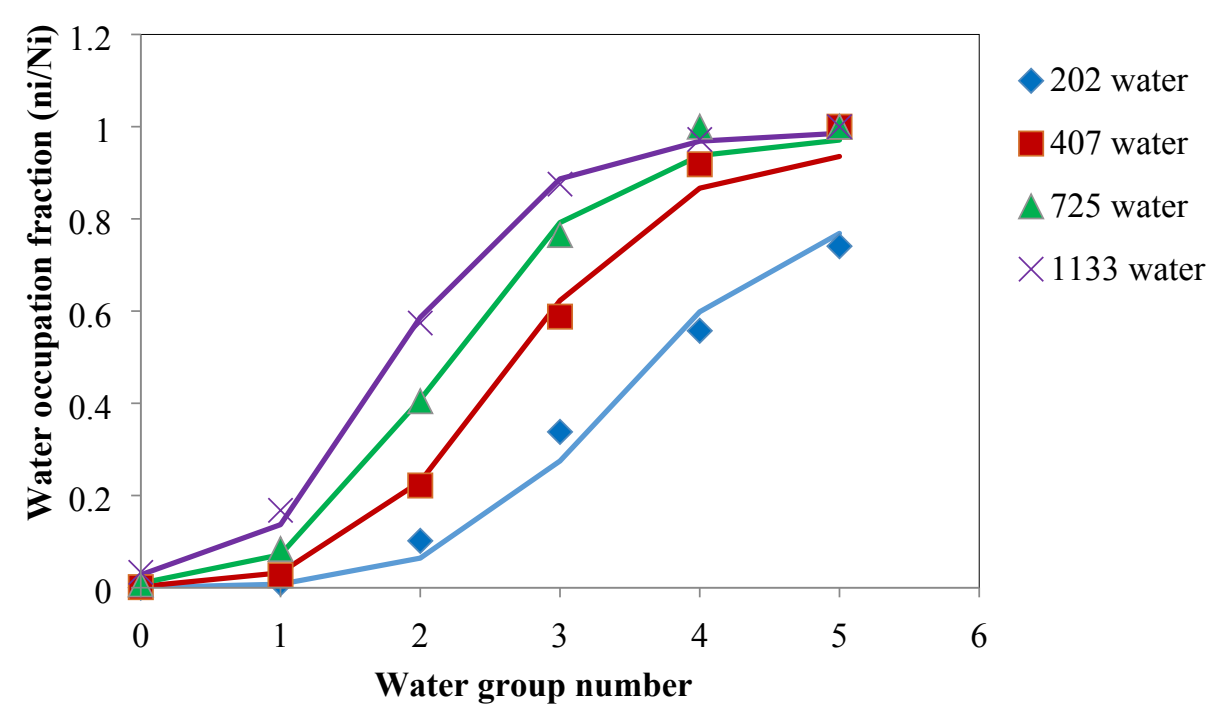

Figure 4. Water occupation fractions in each water group $\left(n_{i} / N_{i}\right)$ for different water sorption levels. The solid lines are the calculated values using Eq. (2) and $E_{i}$ parameters listed in Table 2.

The water sorption isotherm $\left(a_{\mathrm{w}}<0.4\right)$ is calculated based on the proposed model, Eq. (5), and shown in Figure 5. The calculated isotherm is compared to the experimental water adsorption and desorption isotherm $^{36,13}$. The calculations are consistent with the experiments. It should be noted that one data point of the model was from experiments $(8.9 \% \text { water sorption at } 0.35 \text { water activity })^{36,13}$.

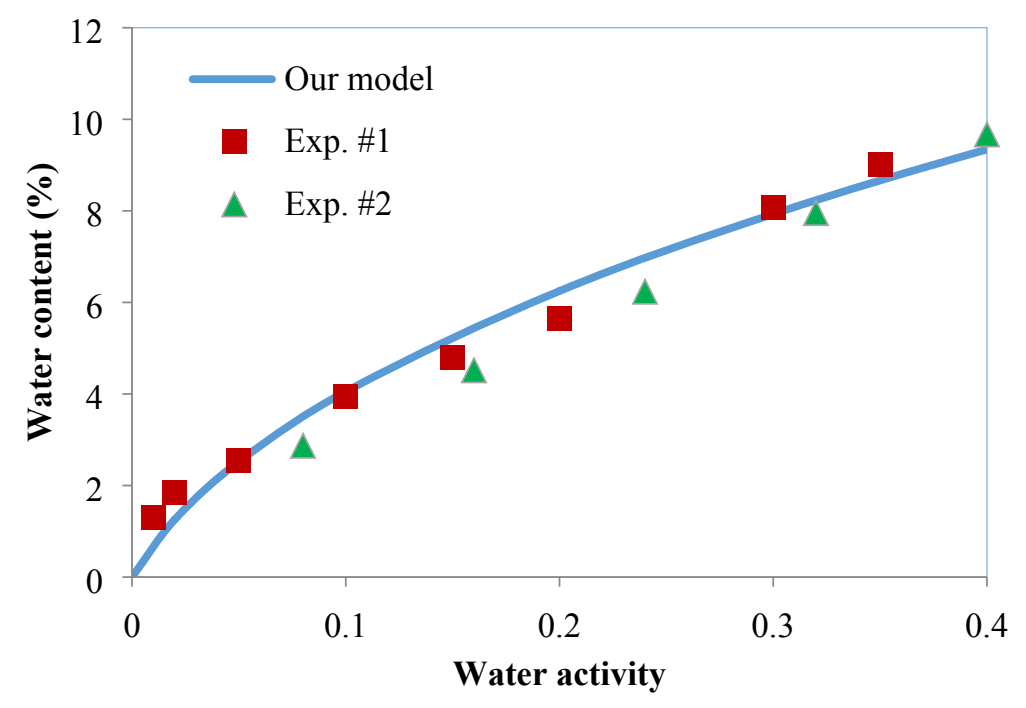

Figure 5. The calculated vapor sorption isotherm based on Eq. (5) (solid line) compared to the experimental water adsorption isotherms: experiment $\# 1^{36}$ and experiment $\# 2^{13}$ for lyophilized IgG1. 


\section{Comparison with BET theory}

The vapor sorption isotherms of lyophilized proteins had been studied experimentally, and the results are commonly fitted to the BET model ${ }^{12,13,36,41}$. The experimental vapor sorption isotherms could fit to the BET model, Eq. (6), well at low water activities. The fitted water monolayer, $W_{\mathrm{m}}$ in Eq. (6), ranged from 5 to $10 \%$. Note, however, that our MD simulations for IgG1 show that the monolayer is not achieved even at much higher water content of $39 \mathrm{wt} \%$. At this level of $39 \mathrm{wt} \%$ (3169 water molecules on each IgG1 molecule), the water subgroup $n_{1}$ (forming $1 \mathrm{HB}$ with protein) still did not reach saturation (Figure 3). This indicates that the water molecules are still not fully covering the protein surface. A representative picture of an IgG1 molecule with 3169 water molecules is shown in Figure 6 demonstrating the partial water coverage (the exposed amino acid side chains colored yellow are hydrophobic residues) - a feature also reported for other proteins ${ }^{26}$. The physical picture is apparently in conflict with the common application of BET's monolayer to describe water sorption to proteins. The question is why the BET equation could still fit to the experimental data. Based on our mechanistic model and Eq. (5), the vapor sorption data can be transformed into the BET plot, i.e. $\frac{a_{w}}{\left(1-a_{w}\right) W}$ as a function of $a_{w}$. Figure 7 shows the transformed data from our model and the experiments. Surprisingly, both our model and the experiments show a very good linear relationship. The results indicate that the BET theory is a good phenomenological model for describing the vapor sorption isotherm of lyophilized proteins although the concept of a BET monolayer should not be applied to protein/water systems. For example, the BET theory assumes homogeneous monolayer water adsorption, with one water molecule acting as a single adsorption site for a water molecule of the upper layer, whereas water molecules sorbed at the protein surface represent a very different type of physical system with a high degree of heterogeneity in water distribution on the protein surface. 


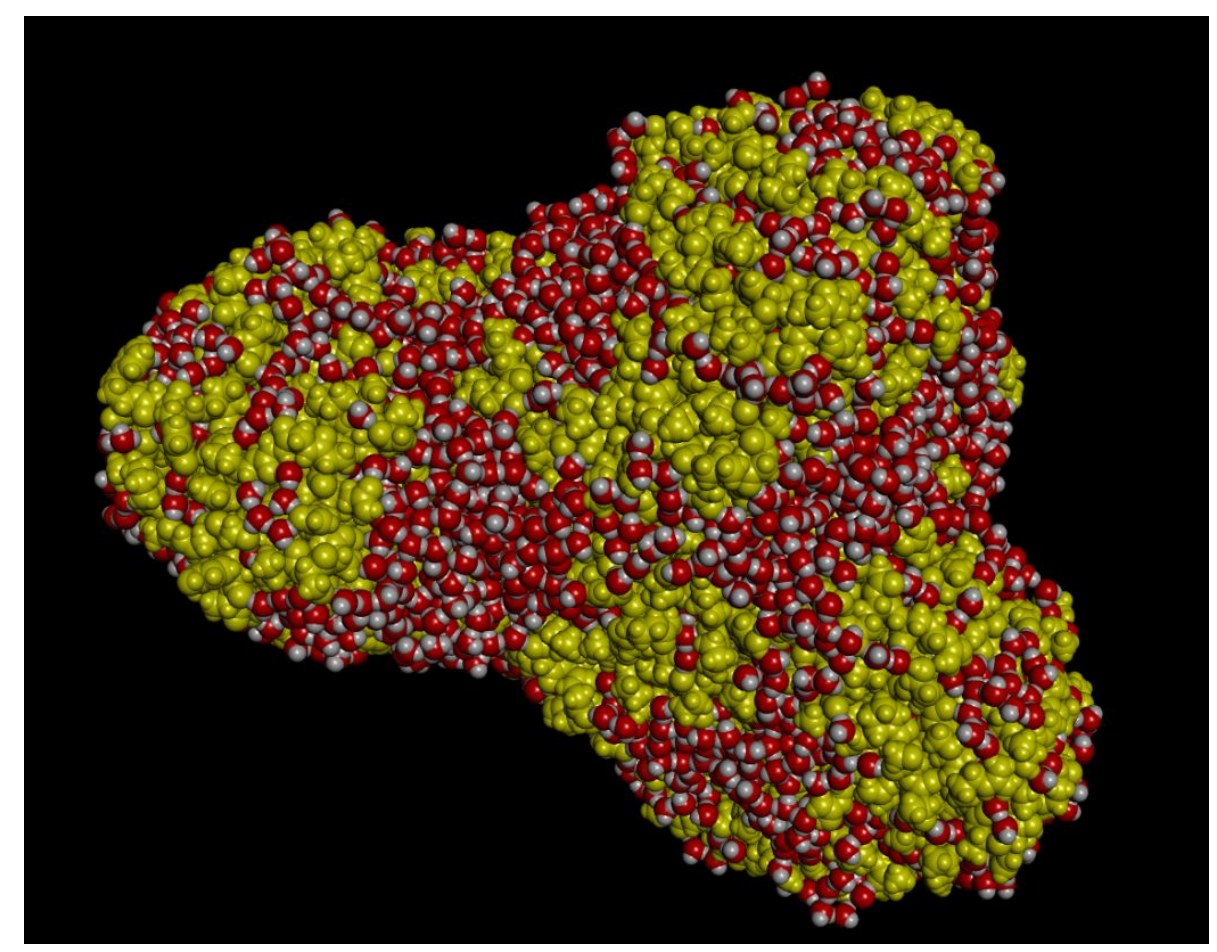

Figure 6. Distribution of water molecules on the IgG1 protein surface. The conformation was extracted from the simulation with 3169 water molecules (the image was generated from the last frame of a 50ns MD simulation). The protein molecule is displayed in van der Waals modus and colored yellow. Water molecules are shown in van der Waals modus and colored red (oxygen) and white (hydrogen).

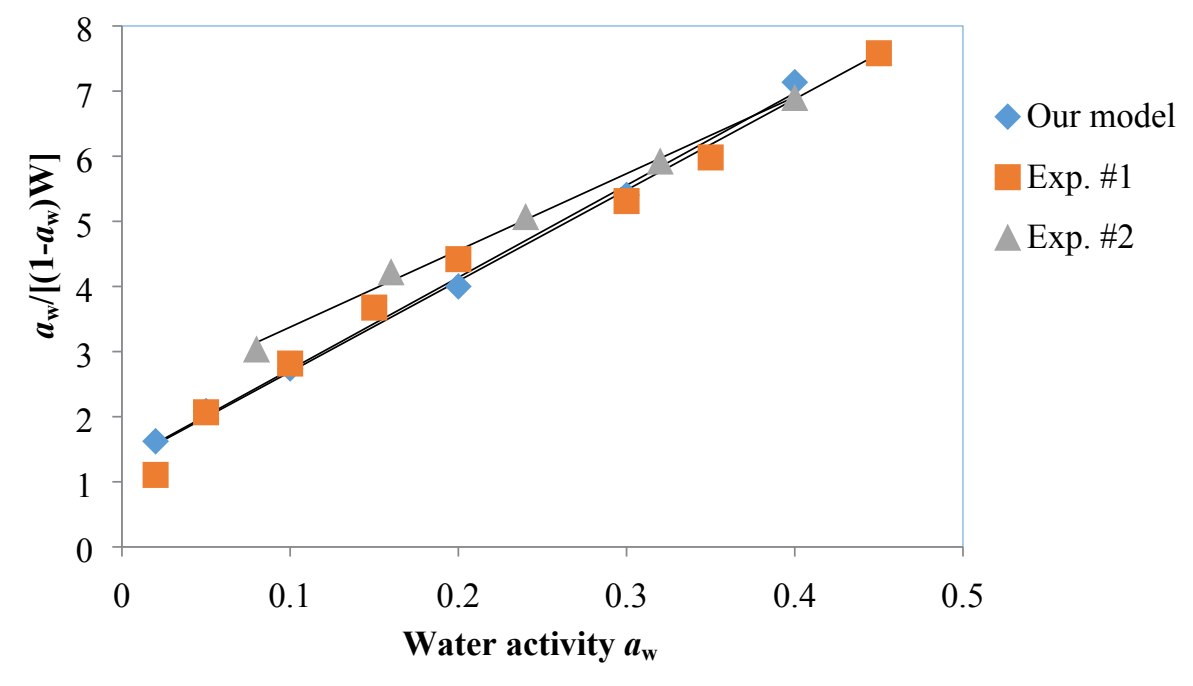

Figure 7. The modified BET plots based on our explicit model, Eq. (5), and two experimental vapor adsorption isotherms ${ }^{36,13}$. 


\section{Physical meaning of the BET "monolayer"}

Despite the phenomenological nature of the BET theory on water sorption in proteins, there are significant efforts to assign a physicochemical meaning to the BET "monolayer" for proteins and organic polymers. Empirically, significant changes in the heat capacity ${ }^{16}$, mobility of water and protein molecules $^{42}$, physicomechanical properties of gelatin ${ }^{43}$, and water plasticization behavior ${ }^{44,45}$ were observed at the BET water "monolayer" level. To examine the physical meaning of the BET "monolayer", the BET "monolayer" level was first determined in our system. Based on Figure 7, the calculated BET "monolayer" level is $6.5 \%\left(W_{\mathrm{m}}=1 /(\right.$ slope + intercept $\left.)\right)$ compared to the experimental BET monolayer level of $6.6 \%{ }^{36}$ and $7.2 \%{ }^{13}$. Figure 8 shows the number of hydrogen bonds between water molecules as a function of water content. The number of HBs between water molecules indicates the formation of water clusters. At low water content, there are not much interactions between water molecules. And at high water content, the number of HBs between water molecules increases linearly with the adsorbed water. A non-linear fitting was carried out on this curve by using the following empirical equation: $\int_{0}^{x} a\left(1-e^{-x / b}\right) d x=a\left[x+b\left(e^{-x / b}-1\right)\right]$, where $a$ is the slope of asymptotic line and $b$ is the offset. The slope $a$ was determined as 1.47 . The offset $b$ indicates a threshold of water clustering and was determined as 615 . This critical point at $\sim 615$ adsorbed water molecules corresponds to $7.5 \mathrm{wt} \%$ of water sorption which is consistent with the BET "monolayer".

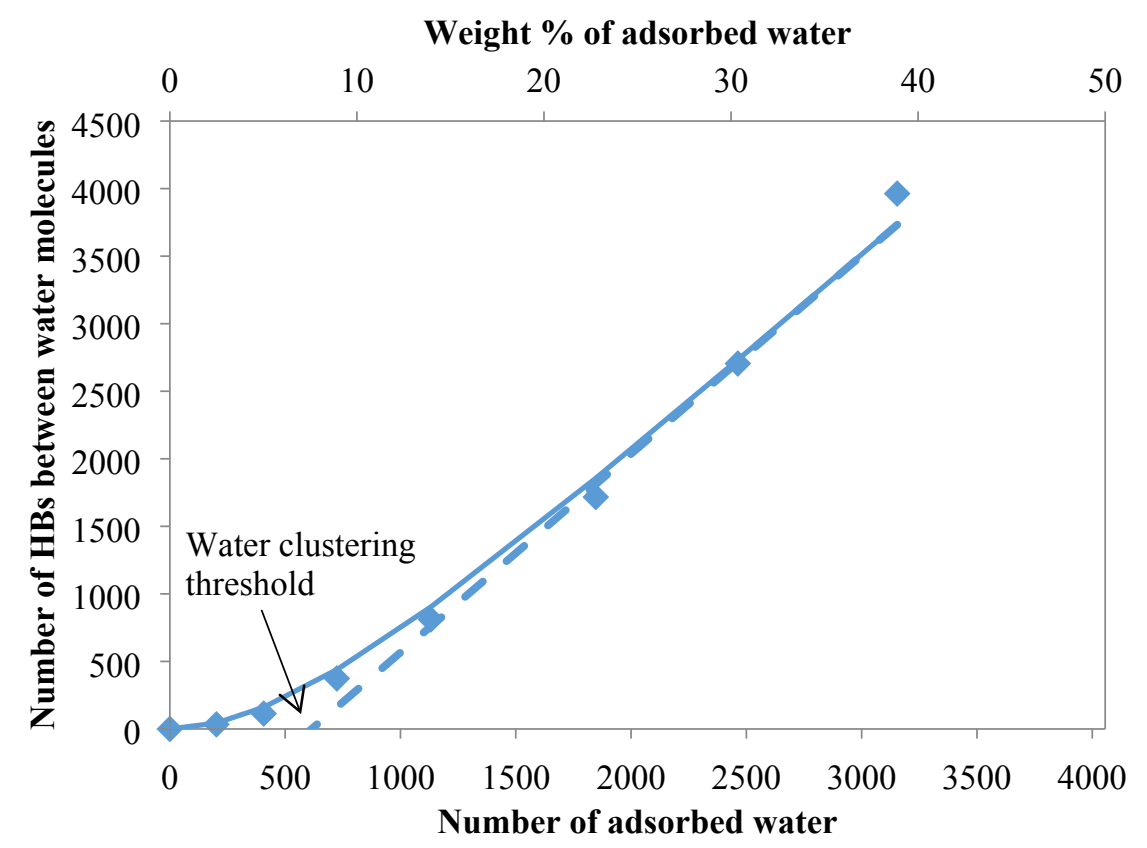

Figure 8. The numbers of HBs between water molecules as a function of total number of adsorbed water molecules. The solid line is the non-linear fitting curve. The dashed line is the asymptotic 


\section{line which intersects with $\mathbf{x}$-axis. The intersection indicates the water-clustering threshold.}

\section{Water distribution on amino acid side chains and backbone}

There were several attempts to predict the BET monolayer level based on the amino acid sequences of proteins. Pauling provided the first model by simply considering one water molecule per polar group, Eq. (9) ${ }^{37}$. Green noticed that Pauling's model often overestimated the BET monolayer level and proposed a modified model that exclude the contributions from side chains that include amino groups, Eq. $(10)^{38}$. The reason for adjusting Pauling's model is the fact that amino groups located at side chains tend to form intra-molecular hydrogen bonds and would not participate in water sorption. The advantage of MD simulations is that the detailed water locations can be explicitly deduced. The hypothesis of Pauling's and Green's models can be tested: whether a 1-on-1 pairing between polar side groups and water molecules exists at the critical water content.

Figure 9 shows the water distributions on different amino acid side chains (a) and the backbone (b) at the BET "monolayer" level. The numbers of hydrogen bonds were counted between water molecules and amino acid side chain. At this critical water content, the average number of hydrogen bonds formed by each water molecule with IgG1 is 2.25 (total number of HB between water and IgG1 molecule divided by the number of water molecules). About $40 \%$ of the total hydrogen bonds were formed with the IgG1 backbone. For the amino acid side chain groups, each of three types of amino acids (Arg, Asp, Glu) could form $\sim 2$ HBs with IgG1; lysine could form $\sim 1 \mathrm{HB}$; each of six amino acids (Asn, Gln, His, Ser, Thr, Tyr) could form $\sim 0.5 \mathrm{HB}$ statistically. Trp has the weakest ability to participate in HB formation $(<0.1 \mathrm{HB})$ although Trp has one HB donor.

Based on the water distributions deduced from MD simulations, the relationship between the critical water content and the primary sequence of the protein has the expression:

$N_{\text {critical }}=\frac{c \cdot N_{\text {total }}+2\left(N_{A r g}+N_{A s p}+N_{G l u}\right)+N_{L y s}+0.5\left(N_{S e r}+N_{T h r}+N_{T y r}+N_{A s n}+N_{G l n}+N_{\text {His }}\right)}{2.25}$

where $c$ is a constant, and equal to 0.33 for $\mathrm{mAb}$; the constant could have a different value for other types of proteins. This new model, Eq. (12), could be used to predict the BET monolayer level based on the primary sequence of a protein. Examples of comparison between the new model and Pauling's and Green's models ${ }^{37,38}$ are shown in Table 3. For the six therapeutic proteins studied, our model provided the closest predictions with standard deviations of $\pm 0.7 \mathrm{wt} \%$ compared to $\pm 1.0 \mathrm{wt} \%$ when using Pauling's model and \pm 1.6 wt $\%$ when using Green's model. 


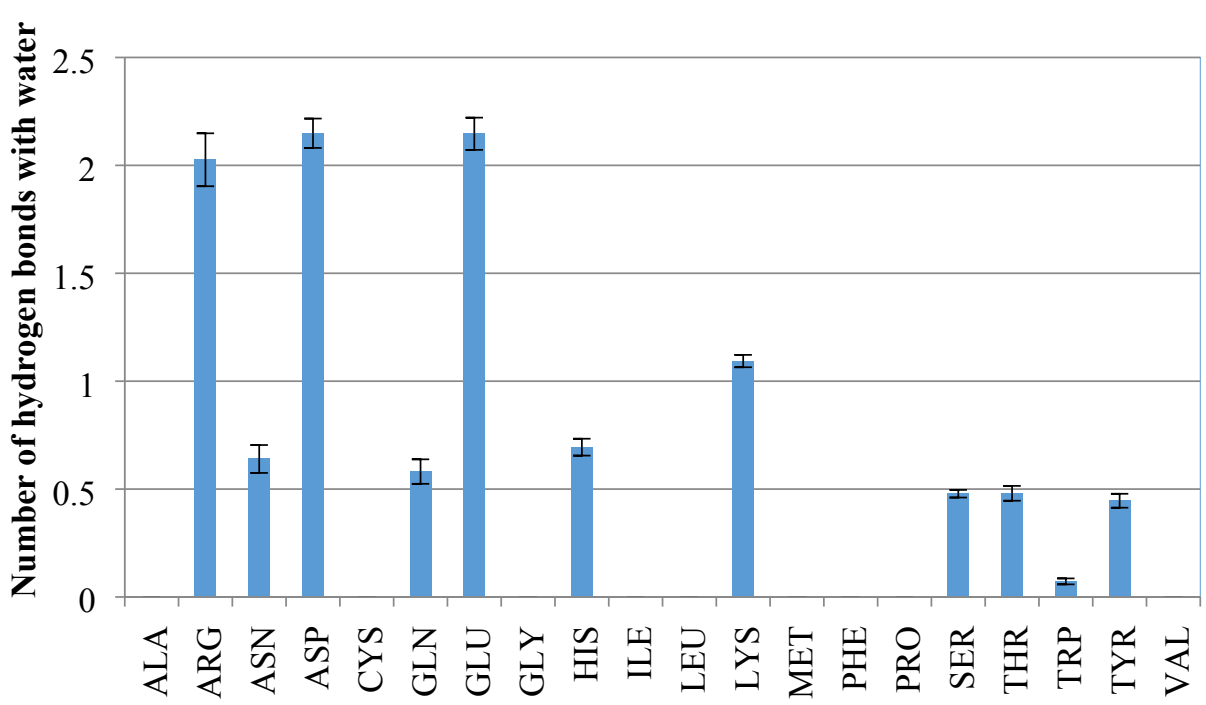

Amino acid side chain

(a)

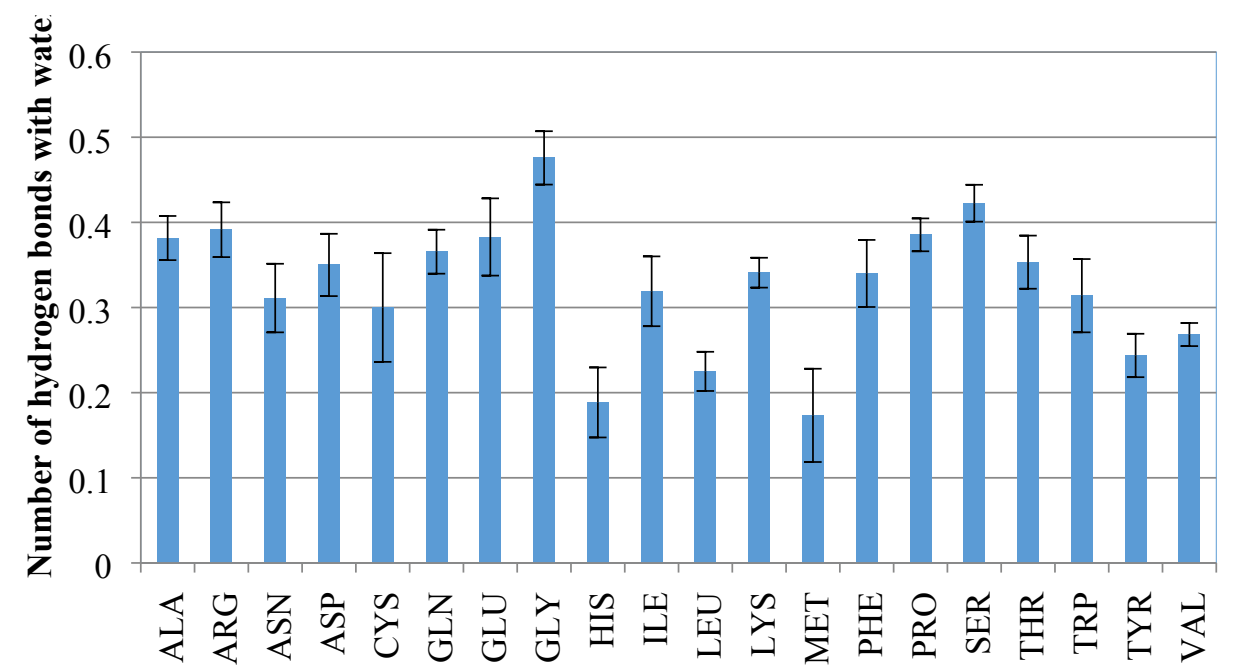

Amino acid backbone

(b)

Figure 9. Water distributions on different amino acid side chain groups (a) and backbone (b) when 513 water molecules were added on one IgG1 molecule. The numbers of HBs were counted between water and IgG1molecules and normalized by the total number of amino acids of the same type. 


\section{Table 3. The comparisons between the experimental BET monolayer of six therapeutic proteins ${ }^{12}$ and the calculated values by our model, Pauling's model and Green's model.}

\begin{tabular}{|c|c|c|c|c|c|}
\hline \multirow[t]{2}{*}{ Proteins } & \multicolumn{2}{|c|}{ Exp. $W_{\mathrm{m}}(\mathrm{wt} \%)^{12}$} & \multicolumn{3}{|c|}{ Calc. $W_{\mathrm{m}}\left(\mathrm{wt}^{\circ} \%\right)$} \\
\hline & $\underset{*}{\text { Traditional }}$ & $\mathrm{GSA}^{+}$ & Our model $^{\wedge}$ & Pauling & Green \\
\hline rhIGF-I & 5.5 & 5.7 & 6.4 & 6.6 & 4.5 \\
\hline rhIFN-g & 6.3 & 6.6 & 6.7 & 7.4 & 4.2 \\
\hline rhGH & 5.4 & 5.3 & 6.3 & 6.9 & 5.0 \\
\hline rhDNase & 6.6 & 6.7 & 6.1 & 6.7 & 5.0 \\
\hline rtPA & 7.0 & 6.2 & 6.1 & 7.1 & 4.4 \\
\hline rhuMAbE25 & 6.9 & 6.5 & 6.0 & 7.9 & 5.8 \\
\hline
\end{tabular}

* Traditional method: Relative humidity controlled by a series of saturated salt solutions in water, water uptake determined by Karl Fisher water titration.

+ GSA method: vapor sorption isotherm determined by using Gravimetric Sorption Analysis instruments.

^The constant "c" in Eq. (12) was using 0.33 for all proteins.

\section{DISCUSSION}

A mechanism-based water sorption model, Eq. (5), is proposed to explain the water sorption isotherm. For water molecules forming more hydrogen bonds with IgG1 (higher i and lower $E_{\mathrm{i}}$, see Table 2), there are limited sites (low $N_{5}$ and $N_{4}$ numbers). With decreasing hydrogen bonds formed by water molecules with IgG1 (lower i and higher $E_{\mathrm{i}}$, see Table 2), the maximum number of water molecules $\left(N_{\mathrm{i}}\right)$ increased exponentially. The parameters $N_{\mathrm{i}}$ and $E_{\mathrm{i}}$ in Table 2 would be protein-specific due to the composition of amino acid types on the surface. But the trend mentioned above would be similar for different protein molecules. The $N_{\mathrm{i}} \sim E_{\mathrm{i}}$ relationship defined the shape of the water sorption isotherm through Eq. (5). One interesting observation from the MD simulations is that the protein structure changes with increasing water sorption. Specifically, the intra-molecular hydrogen bonds that maintain the secondary structure would decrease with increasing water sorption. For example, the number of intra-molecular hydrogen bonds significantly decreased from 1748 with 202 adsorbed water molecules to 987 with 3169 adsorbed water molecules. In comparison, the crystal structure of IgG1 showed 1084 intra-molecular hydrogen bonds which is consistent with hydrated protein (corresponding to $\sim 2620$ adsorbed water molecules on each IgG1 molecule or $\sim 32 \mathrm{wt} \%$ adsorbed water).

We also used the Zimm-Lundberg model ${ }^{15}$ to estimate the size of water clusters. The model was originally derived for quantifying water cluster in polymer-water mixture and to calculate the mean cluster size (MCS) by using the experimental vapor sorption isotherm ${ }^{15}$ :

$$
M C S=1+\phi_{1}\left[-\left(1-\phi_{1}\right)\left[\frac{\partial\left(a_{1} / \phi_{1}\right)}{\partial a_{1}}\right]_{T, P}-1\right]
$$


where $a_{1}$ and $\phi_{1}$ are the water vapor activity and volume fraction, respectively. MCS $=1$ represents a monomer of water, whereas $\mathrm{MCS}=2$ and 3 represent dimer and trimer, respectively. Application of Eq.(13) and using data from Figure 5 resulted in MCS $<0.7$ at a water activity below 0.4 (for the volume fraction of up to $\sim 12 \%$ ). These results are not realistic mainly due to Type II vapor sorption isotherm observed in lyophilized protein system which deviates significantly from the Flory-Huggins model (see Figure 1 of Reference (46) for the description of different types of vapor sorption isotherms). Similarly, high relative humidity for water cluster formation $(>80 \%)$ was determined using Zimm's method for egg and serum albumin ${ }^{47}$. Based on the MD simulations, the water cluster formation was captured in Figure 8. Significant water clustering was formed when the water content is above BET-monolayer level (approx. 615 water molecules per IgG1 molecule, or $7.5 \mathrm{wt} \%$ ). A similar discrepancy between the Zimm's approach and an alternative way to detect water clustering (by FTIR) has also been noticed, with Zimm's treatment predicting much higher values for critical water content/water activity than the experiments by FTIR method ${ }^{15}$.

A formation of 3-d water clusters could have major implications for stability of dried protein formulations. In particular, the water content threshold for formation of 3-d water clusters could be related to a transition from water antiplasticization regime to plasticization of molecular mobility of proteins by water. It has been proposed ${ }^{48,49}$, that small molecules, including water, can serve as antiplasticizers at a lower content, while their plasticization effect became dominant when their content increases above a threshold value. For water in carbohydrate matrixes, in particular, the threshold value of $3-5 \mathrm{wt} \%$ of water was found ${ }^{49,50}$. In addition to molecular mobility implications, formation of the water cluster could facilitate proton transfer in the system, resulting in acceleration of processes which rely on proton transfer, e.g., deamidation reaction. In either case, the increase in water content about the threshold value for 3-d water clusters would be associated with an increase in instability of protein molecules in the dried state.

In our model of predicting BET monolayer level, Eq. (12), the contributions from protein backbone were considered first. According to the MD simulations, among all the hydrogen bonds between water molecules and protein, about $40 \%$ of the HBs were formed with protein backbone. Regarding the contributions from the side chains, instead of using a simple 1:1 ratio between polar amino acid and water molecules as done by Pauling and Green $^{37,38}$, different weights were assigned to different amino acids based on water distribution results. For example, Asp and Glu would attract $\sim 1(2 / 2.25)$ water 
molecule per residue which is similar to Pauling's and Green's models; Lys would attract about half (1/2.25) water molecule per residue; Ser/Thr/Tyr/His/Gln/Asn would only attract about one fourth $(0.5 / 2.25)$ water molecule per residue which is much lower than in Pauling's and Green's models. The two amino acids Gln and Asn were not considered as polar groups in Pauling's and Green's models. However, the HB forming capability of the two residues makes them contribute to water sorption. On the other hand, although Trp side chain could form HB and was considered as a polar group by Pauling and Green, the contributions to water sorption is almost negligible $\left(\sim 0.03 \mathrm{H}_{2} \mathrm{O}\right.$ per residue $)$ based on the MD simulations and is therefore excluded in our model.

\section{CONCLUSION}

By explicitly simulating water sorption on the IgG1 protein surface, we show the heterogeneity of water distribution on the protein surface at different water contents. By grouping the adsorbed water molecules using hydrogen bonding network analysis, an explicit water sorption model was built and was consistent with the experimental water sorption isotherms. Transforming the explicit model into a BET plot demonstrates that the BET theory is a good phenomenological model applied to lyophilized protein systems. The BET parameter $W_{\mathrm{m}}$ is related to the onset of water cluster formation. To predict the parameter $W_{\mathrm{m}}$ based on primary sequence of protein, the contributions from both polar side chains and protein backbones should be considered. For polar chains, different amino acids have different abilities to attract water molecules.

\section{ACKNOWLEGEMENTS}

Simulations were performed on the CPU/GPU cluster at DTU Chemistry and the High Performance Computing cluster at DTU.

\section{REFERENCES}

(1) Ryberg, L. A.; Sonderby, P.; Barrientos, F.; Bukrinski, J. T.; Peters, G. H. J.; Harris, P. Solution structures of long-acting insulin analogues and their complexes with albumin. Acta Cryst. D 2019, 75, 272-282.

(2) Serna, N.; Sánchez-García, L.; Unzueta, U.; Díaz, R.; Vázquez, E.; Mangues, R.; Villaverde, A. Protein-Based Therapeutic Killing for Cancer Therapies. Trends in Biotechnology 2018, 36, 318-335. (3) Wagner E. K.; Maynard J. A. Engineering therapeutic antibodies to combat infectious diseases. Curr Opin Chem Eng. 2018, 19, 131-141. 
(4) Batty, P.; Lillicrap, D. Advances and challenges for hemophilia gene therapy. Human Molecular Genetics 2019, 28(R1), R95-R101,

(5) Arlet, J.-B.; Guillem, F.; Lamarque, M.; Dussiot, M.; Maciel, T. Moura, I.; Hermine, O.; Courtois, G. Protein-based therapeutic for anemia caused by dyserythropoiesis. Expert Review of Proteomics 2016, 13(11), 983-992.

(6) Li, J.; Krause, M. E.; Chen, X.; Cheng, Y.; Dai, W.; Hill, J. J.; Huang, M.; Jordan, S.; LaCasse, D.; Narhi, L.; Shalaeve, E.; Shieh, I. C.; Thomas, J. C.; Tu, R.; Zheng, S.; Zhu, L. Interfacial stress in the development of biologics fundamental understanding, current practice, and future perspective. AAPS J. 2019, $21,44$.

(7) Emami, F.; Vatanara, A.; Park, E. J.; Na, D. H. Drying technologies for the stability and bioavailability of biopharmaceuticals. Pharmaceutics 2018, 10, 131.

(8) Pikal, M. J. Lyophilization. In Encyclopedia of harmaceutical Technology, Swarbrick, J. and Boylan, J. Ed.; Marcel Dekker, New York, 2002, 1299-1326.

(9) Franks, F.; Auffret, T. In Freeze-drying of pharmaceuticals and biopharmaceuticals. Principles and practice. RSC Publishing, Cambridge, 2007, 2006.

(10) Hill, J. J.; Shalaev, E. Y.; Zografi, G. Thermodynamic and dynamic factors involved in the stability of native protein structure in amorphous solids in relation to levels of hydration. J. Pharm. Sci. 2005, 94, 1636-1667.

(11) Ohtake, S.; Feng, S.; Shalaev E. Effect of water on the chemical stability of amorphous pharmaceuticals: 2. Deamidation of peptides and proteins. J. Pharm. Sci. 2018, 107, 42-56.

(12) Costantino, H. R.; Curley, J. G.; Hsu, C. C. Determining the water sorption monolayer of lyophilized pharmaceutical proteins. J. Pharm. Sci. 1997, 86, 1390-1393.

(13) Wang, B.; Tchessalov, S.; Warne, N. W.; Pikal, M. J. Impact of sucrose level on storage stability of proteins in freeze-dried solids: I. Correlation of protein-sugar interaction with native structure preservation. J. Pharm. Sci. 2009, 98, 3131-3144.

(14) Hageman M. J. Water sorption and solid-state stability of proteins. In Stability of Protein Pharmaceutics; Ahern T. J. and Manning, M.C. Ed.; Plenum Press, New York, 1992, 273-309.

(15) Davis, E. M.; Elabd Y. A. Water clustering in glassy polymers. J. Phys. Chem. B 2013, 117, 1062910640.

(16) Rupley, J. A.; Gratton, E.; Careri, G. Water and globular proteins. Trends Biochem. Sci. 1983, 8, 18-22.

(17) Banik, S. D.; Nordblad, M.; Woodley, J. M.; Peters, G.H. Effect of water clustering on the activity 
of Candida antarctica lipase B in organic medium. Catalysts 2017, 7, 227.

(18) Bellissent-Funel, M.-C.; Hassanali, A.; Havenith, M.; Henchman, R.; Pohl, P. Sterpone, F. van der Spoel, D.; Xu, Y.; Garcia, A. E. Water determines the structure and dynamics of proteins. Chemical Reviews 2016, $116(13), 7673-7697$

(19) Catak, S.; Monard, G.; Aviyente, V.; Ruiz-Lopez, M. F. Deamidation of asparagine residues: direct hydrolysis versus succinimide-mediated deamidation mechanism. J. Phys. Chem. A 2009, 113, 11111120.

(20) Stegmann, C. M.; Seeliger, D.; Sheldrick, G. M.; de Groot, B. L.; Wahl, M. C. The thermodynamic influence of trapped water molecules on a protein-ligand interaction. Angew. Chem. Int. Ed. Engl. 2009, 48, 5207-5210.

(21) Heyden, M. Heterogeneity of water structure and dynamics at the protein-water interface. J. Chem. Phys. 2019, 150, 094701.

(22) Urbic, T.; Dias, C. L. Hydration of non-polar anti-parallel $\beta$-sheets. J. Chem. Phys. 2014, 140, 165101 .

(23) Ben-Shalom, I. Y.; Lin, C.; Kurtzman, T.; Walker, R. C.; Gilson, M. K. Simulating water exchange to buried binding sites. J. Chem. Theory Comput. 2019, 15, 2684-2691.

(24) Tarek, M.; Tobias, D. J.; The dynamics of protein hydration water: a quantitative comparison of molecular dynamics simulations and neutron-scattering experiments. Biophys. J. 2000, 79, 3244-3257.

(25) Li, D.; Liu, L.; Yu, H.; Zhai, Z.; Zhang, Y.; Guo, B.; Yang, C.; Liu, B. A molecular simulation study of the protection of insulin bioactive structure by trehalose. J. Mol. Model. 2014, 20, 2496.

(26) Branco, R. J. F.; Graber, M.; Danis, V.; Pleiss. J. Molecular mechanism of the hydration of Candida antarctica lipase B in the gas phase: water adsorption isotherms and molecular dynamics simulations. ChemBioChem 2009, 10, 2913-2919.

(27) Kale, L.; Skeel, R.; Bhandarkar, M.; Brunner, R.; Gursoy, A.; Krawetz, N.; Phillips, J.; Shinozaki, A.; Varadarajan, K.; Schulten, K. NAMD2: Greater scalability for parallel molecular dynamics. J. Comp. Phys. 1999, 151, 283-312.

(28) Saphire, E. O.; Parren, P. W.; Pantophlet, R.; Zwick, M. B.; Morris, G. M.; Rudd, P. M.; Dwek, R. A.; Stanfield, R. L.; Burton, D. R.; Wilson, I. A. Crystal structure of a neutralizing human IgG against HIV-1: a template for vaccine design. Science 2001, 293, 1155-1159.

(29) Bernstein, F. C.; Koetzle, T. F.; Williams, G. J.; Meyer, E. E.; Brice, M. D.; Rodgers, J. R.; Kennard, O.; Shimanouchi, T.; Tasumi, M. The Protein Data Bank: a computer-based archival file for macromolecular structures. J. Mol. Biol. 1977, 112, 535-542. 
(30) Best, R. B.; Zhu, X.; Shim, J.; Lopes, P.; Mittal, J.; Feig, M.; MacKerell, A. D. Optimization of the additive CHARMM all-atom protein force field targeting improved sampling of the backbone phi, psi and sidechain chi1 and chi2 dihedral angles, J. Chem. Theory Comput. 2012, 8, 3257-3273.

(31) Jorgensen, W. L.; Chandrasekhar, J.; Medura, J. D.; Impey, R. W.; Klein, M. L. Comparison of simple potential models for simulating liquid water. J. Chem. Phys. 1983, 79, 926-935.

(32) Paterlini, M. G.; Ferguson, D. M. Constant temperature simulations using the Langevin equation with velocity Verlet integration. Chemical Physics 1998, 236, 243-252.

(33) Humphrey, W.; Dalke, A.; Schulten, K. VMD - Visual Molecular Dynamics. J. Mol. Graph. 1996, 14, 33-38.

(34) Guardia, E.; Skarmoutsos, I.; Masia, M. Hydrogen bonding and related properties in liquid water: a Car-Parrinello molecular dynamics simulation study. J. Phys. Chem. B 2015, 119, 8926-8938.

(35) Brunauer, S.; Emmett, P. H.; Teller, E. Adsoption of gases in multimolecular layers. J. Am. Chem. Soc. 1938, 60, 309-319.

(36) Chang, L. ; Shepherd, D. ; Sun, J. ; Tang, X. ; Pikal, M. J. Effect of sorbitol and residual moisture on the stability of lyophilized antibodies: Implications for the mechanism of protein stabilization in the solid state. J. Pharm. Sci. 2005, 94, 1445-1455.

(37) Pauling, L. The adsorption of water by proteins. J. Am. Chem. Soc. 1945, 67, 555-557.

(38) Green, R.W. The adsorption of water vapour on casein. Trans. Royal Soc. New Zealand 1948, 77, 313-317.

(39) Weibull, W. J. A statistical distribution function of wide applicability. Appl. Mechanics 1951, 18, 293-297.

(40) Findenegg, G. H.; Jahnert, S.; Akcakayiran, D.; Schreiber, A. Freezing and melting of water confined in silica nanopores. ChemPhysChem 2008, 9, 2651-2659.

(41) Luthra, S.; Lechuga-Ballesteros, D.; Kalonia, D. S.; Pikal, M. J. Simultaneous measurement of water desorption isotherm and heats of water desorption of proteins using perfusion isothermal microcalorimetry. J. Pharm. Sci. 2007, 96, 1974-1982.

(42) Parak, F. Correlations of protein dynamics with water mobility: Mossbauer spectroscopy and microwave absorption methods. Methods Enzymol. 1986, 127, 196-206.

(43) Kontny, M. J.; Mulski, C. A. Gelatin capsule brittleness as a function of relative humidity at room temperature. Int. J. Pharm. 1989, 54, 79-85.

(44) Kakivaya, S. R.; Hoeve, C. A. J. The glass point of elastin. Proc. Nat. Acad. Sci. 1975, 72, 35053507. 
(45) Levine, H.; Slade, L. Water as a plasticizer: Physico-chemical aspects of low moisture polymeric systems. In Water Science Reviews Vol. 3; Franks, F., Ed.; Cambridge University Press, Cambridge, 1987, 79-185.

(46) Zhang, J. ; Zografi G. The relationship between "free volume"-derived parameters for water vapor absorption into amorphous solids. J. Pharm. Sci. 2000, 89, 1063-1072.

(47) Starkweather, H. W. Clustering of water in polymers. J. Polym. Sci. 1963, 1, 133-138.

(48) Cicerone, M. T.; Pikal, M. J.; Qian, K. K. Stabilization of proteins in solid form. Advanced Drug Delivery Reviews 2015, 93, 14-24.

(49) Roussenova, M.; Murith, M.; Alam, A.; Ubbink, J. Plasticization, anti-plasticization and molecular packing in amorphous carbohydrate-glycerolmatrices. Biomacromolecules 2010, 11, 3237-3247.

(50) Townrow, S.; Roussenova, M.; Giardiello, M.; Alam, A.; Ubbink, J. Specificvolume-hole volume correlations in amorphous carbohydrates: Effect of tem-perature, molecular weight, and water content.

J. Phys. Chem. B 2010, 114, 1568-1578. 